\title{
A
}

Acta HealthMedica

Acta HealthMedica (ISSN: 2414-6528)

http://www.ActaHealthMedica.com

Volume 3, Issue 1, February 2018, Pages: 235, DOI: http://dx.doi.org/10.19082/ah235

\section{EPIDEMIO-GENETIC CHARACTERIZATION OF THE POPULATION OF TLEMCEN (NORTH- WEST ALGERIA) BY TRISOMY 21}

\author{
Houari Hamdaoui ${ }^{1,2}$ Ammaria Aouar ${ }^{1,1}$, Djamel Belkhatir ${ }^{1}$, Zakarya Moqaddem ${ }^{1,2}$, Sarra Khater ${ }^{1,2}$, Nafissa \\ Chaabni $^{2}$
}

1: Laboratory of human actions' valorisation for protection of environment and application in public health, University of Tlemcen, Algeria

2: CancerLab Laboratory, University of Tlemcen, Algeria

3: Laboratory of Anthropology, University of Tlemcen, Algeria

hhowarih@hotmail.fr

\section{TYPE OF ARTICLE: CONFERENCE ABSTRACT}

\begin{abstract}
Background: Trisomy 21 or Down syndrome is the first chromosomal aberration described in humans. It is the most common case of abnormal chromosome number with an occurrence of $1 / 800$ live births. There are 6 million cases worldwide. Nearly 80,000 cases of trisomy 21 are documented in Algeria. The objective of our study is to give an epidemiological profile of Tlemcen's population with trisomy 21.

Methods: This is a prospective study of 38 children diagnosed with trisomy 21, who present a specific clinical picture to this syndrome (mental retardation, dysmorphic syndrome, presence of congenital malformations, etc.). Children are admitted to two mental psychological centers for mentally ill children (PPCs) located in the south of Tlemcen (19 in the PPC of Sebdou, 10 in the PPC of Sid Djilali) and the Union of the Mentally Deprived (UMD) association of Tlemcen - (9 children). For this study we had the consent of the parents of each child. We collected data using a pre-established questionnaire for parents and by referring to the medical and administrative records of the children. Data included age, sex and birth order, mother's age, father's age, presence of a history of the syndrome, consanguineous parental marriage, and number of miscarriages in the mother.

Results : The children's population with Down syndrome is aged between 4 years to 23 years old (among them, $48.65 \%<10$ years old, $40.55 \%$ between 10 years to 18 years old, and $10.8 \%>18$ years old). The sex ratio is 5 males to 4 females. Our results do not present an influence of consanguinity on the occurrence of Down syndrome (only $17.14 \%$ of trisomic children are from a consanguineous marriage, compared to $82.86 \%$ from non-consanguineous marriages) and for the 38 children diagnosed with trisomy 21 , no child has a history of this syndrome. On the other hand, maternal age is incriminated as a risk factor for occurrence of this pathology because in about $60 \%$ of cases the maternal age is greater than 35 years old, in $10 \%$ between 30 years to 35 years old, and in $30 \%$ less than 30 years old.
\end{abstract}

Conclusions: Down syndrome remains the most common chromosomal aberration in Tlemcen's population as compared with other world populations. The occurrence of this syndrome is strongly correlated with advanced maternal age, however, in order to better understand the prediction of this syndrome, we should increase the number of samples analyzed with studying other factors.

KEYWORDS: Trisomy 21, Tlemcen's population, Algerian Northwest, Epidemio-genetics, Maternal age.

\footnotetext{
Abstracts of Second International Conference on Health Sciences and Medical Technologies, 10-12 October 2017, Tlemcen, Algeria (ICHSMT-17)

(C) 2018 The Authors. This is an open access article under the terms of the Creative Commons Attribution-NonCommercialNoDerivs License, which permits use and distribution in any medium, provided the original work is properly cited, the use is non-commercial and no modifications or adaptations are made.
} 